\title{
Students' Perception of Problem-based Learning Conducted in Phase1 Medical Program, UCSI University, Malaysia
}

\author{
Naw May Emerald ${ }^{1}$, Phyu Phyu Aung ${ }^{2}$, Thu Zar Han ${ }^{2}$, Khin Than Yee ${ }^{1}$, Myo Hla Myint ${ }^{1}$, \\ Thwe Thwe Soe ${ }^{1}$, San San Oo
}

\begin{abstract}
Problem-based learning (PBL) has been introduced in the Phase 1 curriculum of Doctor of Medicine programme at Faculty of Medicine \& Health Sciences, UCSI University since its inception in 2005. The main objective of this study was to investigate the perception of medical students on problembased learning sessions. A cross sectional study was conducted on a total of 115 medical students from June 2011 to June 2012. Forty nine (42.6\%), 31(27\%) and 35(30.4\%) medical students from first, second and third years respectively participated in the study. The questionnaire included 23 statements to assess the benefits and disadvantages of PBL and the requirements in PBL sessions. Findings revealed that the majority agreed with statements on benefits - PBL motivates students for self-learning $(80.9 \%)$, enhances discovery of learning issues $(78.3 \%)$, provides critical thinking skills $(71.3 \%)$, improves communication skills (80\%) and enhances in obtaining new information (85.2\%). Sixty percent $(n=69)$ responded that PBL was time consuming and $84(73.1 \%)$ noted that some students dominate while others are passive in the discussion. Overall positive perception on effectiveness of PBL on students' learning was obtained in $79(68.7 \%)$ of respondents and the highest agreement was observed among the second year students (93.5\%).
\end{abstract}

Key words: PBL, medical students

\section{Introduction}

Problem-based learning (PBL) in medical education began with the Faculty of Medicine at McMaster University, Canada in 1969. Since then, several medical schools worldwide have been implementing $\mathrm{PBL}$ in their curriculum. PBL provides significant effectiveness to students in developing critical thinking and problem solving skills as well as life-long learning habits (Amin \& Khoo, 2009).

\footnotetext{
${ }^{1}$ Senior Lecturer

${ }^{2}$ Associate Professor

Faculty of Medicine \& Health Sciences, UCSI University, Kuala Lumpur, Malaysia.
}

Corresponding Author:

Dr. Naw May Emerald

Senior Lecturer, Faculty of Medicine \& Health Sciences UCSI University

No.1, Jalan Menara Gading, UCSI Height, Taman

Connaught, Cheras, 56000, Kuala Lumpur, Malaysia.

Email: nawme@ucsi.edu.my
PBL was introduced at the Faculty of Medicine \& Health Sciences, UCSI University, since the inception of medical programme in 2005. Although implemented, students' perception on PBL has not been reviewed. Students' perceptions are important in order to improve the teaching-learning strategy used in PBL.

This study was aimed to explore the perception of Phase 1 medical students on implemented PBL sessions and compare perceptions between different academic years.

\section{Methodology}

The study was a cross sectional study in which a total of 115 Phase 1 medical students were recruited.The study group included 49 students from year 1,31 students from year 2 and 35 students who have recently passed year 2 professional examination before proceeding to clinical year. The study was performed in UCSI University from June 2011 to June 2012. 
Data collection was by a self-administered pretested structured questionnaire, designed based on existing literature (Amin \& Khoo, 2009; Barman et al., 2006). The questionnaire included 23 statements assessing the benefits, disadvantages and requirements in PBL. Students' perception was measured by 5-point Likert scale. Data was analyzed by SPSS for windows version 16. The Kruskal-Wallis test was used to test the statistical significance.

\section{Results}

A majority perceived that PBL motivates students for self-learning (80.9\%), enhances discovery of learning issues $(78.3 \%)$, provides critical thinking skills $(71.3 \%)$, improves communication skills $(80 \%)$ and that they obtain new information from PBL (85.2\%). However, half of the students $(50.4 \%)$ disagreed with the statement 'PBL is effective without having a lecture on the same topic'. Nearly half $(40.9 \%)$ of students agreed that it was easy to memorize the facts after PBL while $22.6 \%$ disagreed and $36.5 \%$ gave neutral response. When responding to statements on disadvantages of PBL, the majority agreed that PBL was time consuming $(60 \%)$ and that some students dominate while others are passive in the discussion (73.1\%). More than half of the students agreed with the statement assessing the requirements of PBL sessions. Those include adequate allotment of time for each PBL session (73\%), adequate learning resources are available from internet $(53.9 \%)$ and that rooms for group discussion were comfortable (61.8\%). However, only $31.3 \%$ agreed that enough learning resources are available in the library. An overall positive perception on effectiveness of PBL on students' learning was observed in 79(68.7\%) of respondents (Table 1).

Table 1: Frequency distribution of students' responses on $\mathrm{PBL}$

\begin{tabular}{|c|c|c|c|}
\hline Questionnaires & $\begin{array}{c}\text { SDI D } \\
\text { number (\%) }\end{array}$ & $\begin{array}{c}\text { Neutral } \\
\text { number (\%) }\end{array}$ & $\begin{array}{c}\text { A/SA } \\
\text { number (\%) }\end{array}$ \\
\hline Motivates students for self-learning & $7(6 \%)$ & $15(1 \%)$ & $93(80.9 \%)$ \\
\hline Enhances to find out learning issue from the given problems & $6(5.2 \%)$ & $19(16.5 \%)$ & $90(78.3 \%)$ \\
\hline Allows in-depth understanding of the topics & $15(13 \%)$ & $39(34 \%)$ & $61(53 \%)$ \\
\hline Provides problem analyzing skill & $9(7.8 \%)$ & $27(23.5 \%)$ & $79(68.7 \%)$ \\
\hline Provides critical thinking skill & $11(9.6 \%)$ & $22(19.1 \%)$ & $82(71.3 \%)$ \\
\hline Communication skill is improved & $1(0.9 \%)$ & 22(19.1\%) & $92(80 \%)$ \\
\hline Creates voluntary spirit among students & $10(8.7 \%)$ & $42(36.5 \%)$ & $63(54.8 \%)$ \\
\hline Enhances the habit of active participation in group & $12(10.4 \%)$ & $29(25.2 \%)$ & $74(64.4 \%)$ \\
\hline Easy to memorize the facts after PBL sessions & $26(22.6 \%)$ & $42(36.5 \%)$ & $47(40.9 \%)$ \\
\hline Obtain new information from PBL sessions & $4(3.5 \%)$ & $13(11.3 \%)$ & $98(85.2 \%)$ \\
\hline Get practice for lifelong learning & $13(11.3 \%)$ & $38(33 \%)$ & $64(55.7 \%)$ \\
\hline PBL is effective without having lecture of same topic & $58(50.4 \%)$ & $36(31.3 \%)$ & $21(18.3 \%)$ \\
\hline Enhances the practice of co-operative and collaborative learning & $11(9.6 \%)$ & $31(26.9 \%)$ & $73(63.5 \%)$ \\
\hline Enhance the practice of identifying learning resources & $7(6.1 \%)$ & $31(26.9 \%)$ & $77(67 \%)$ \\
\hline Have experience of group leadership & $8(6.9 \%)$ & $41(35.7 \%)$ & $66(57.4 \%)$ \\
\hline $\begin{array}{l}\text { Takes too much time for preparation of presentation (time } \\
\text { consuming) }\end{array}$ & $17(14.8 \%)$ & $29(25.2 \%)$ & $69(60 \%)$ \\
\hline Some students dominate while others are passive in the discussion & $9(7.8 \%)$ & $22(19.1 \%)$ & $84(73.1 \%)$ \\
\hline Didactic lectures are more effective than PBL sessions & $19(16.5 \%)$ & $52(45.2 \%)$ & $44(38.3 \%)$ \\
\hline Time allotted for each PBL session is enough & $11(9.6 \%)$ & $20(17.4 \%)$ & $84(73 \%)$ \\
\hline Enough learning resources are available in library & $45(39.1 \%)$ & $34(29.6 \%)$ & $36(31.3 \%)$ \\
\hline Enough learning resources are available from internet & $14(12.2 \%)$ & $39(33.9 \%)$ & $62(53.9 \%)$ \\
\hline Rooms for group discussion are comfortable & $25(21.7 \%)$ & $19(16.5 \%)$ & $71(61.8 \%)$ \\
\hline Overall , PBL is effective for student's learning & $12(10.4 \%)$ & $24(20.9 \%)$ & $79(68.7 \%)$ \\
\hline
\end{tabular}

*SD = Strongly disagree, $D=$ Disagree, $A=$ Agree, $S A=$ Strongly agree 
Table 2: Comparison of the students' responses to the statements by academic year

\begin{tabular}{|c|c|c|c|c|c|}
\hline Questionnaires & $\begin{array}{l}\text { Year } 1 \\
\text { Mean } \\
\text { Rank }\end{array}$ & $\begin{array}{l}\text { Year } 2 \\
\text { Mean } \\
\text { Rank }\end{array}$ & $\begin{array}{l}\text { Year } 3 \\
\text { Mean } \\
\text { Rank }\end{array}$ & $x^{2}$ & $\begin{array}{c}\text { p- } \\
\text { value }\end{array}$ \\
\hline Motivates students for self-learning & 46.94 & 67.47 & 65.10 & 12.703 & .002 \\
\hline $\begin{array}{l}\text { Enhances to find out learning issue from the given } \\
\text { problems }\end{array}$ & 44.11 & 69.71 & 67.07 & 19.741 & .000 \\
\hline Provides problem analyzing skill & 48.99 & 67.61 & 62.10 & 7.842 & .020 \\
\hline Provides critical thinking skill & 46.39 & 71.32 & 62.46 & 14.116 & .001 \\
\hline Creates voluntary spirit among students & 50.44 & 69.68 & 58.24 & 7.22 & .027 \\
\hline Enhances the habit of active participation in group & 48.51 & 61.13 & 68.51 & 9.126 & .010 \\
\hline Easy to memorize the facts after PBL sessions & 46.50 & 66.18 & 66.86 & 11.034 & .004 \\
\hline Obtain new information from $\mathrm{PBL}$ sessions & 48.37 & 64.52 & 65.71 & 9.526 & .009 \\
\hline $\begin{array}{l}\text { Takes too much time for preparation of presentation. } \\
\text { (time consuming) }\end{array}$ & 69.44 & 42.37 & 55.83 & 13.737 & .001 \\
\hline Didactic lectures are more effective than PBL sessions & 66.81 & 54.34 & 48.91 & 7.204 & .027 \\
\hline Time allotted for each PBL sessions is enough & 51.63 & 70.69 & 55.67 & 8.314 & .016 \\
\hline Enough learning resources are available in library & 58.76 & 71.87 & 44.66 & 11.800 & .003 \\
\hline Overall , PBL is effective for student's learning & 47.53 & 73.44 & 58.99 & 14.532 & .001 \\
\hline
\end{tabular}

Students' responses were compared according to mean rank by academic year. It showed that higher percent of 2 nd and 3 rd year students gave positive responses to the benefits of PBL than 1st year students. First years reported more frequent agreement with regards to disadvantages of PBL compared to other students. Significant differences by academic year were observed in the statements shown in Table 2. In viewing of overall students' perception on effectiveness of PBL on students' learning, the mean rank of 2nd year students' perception was higher than year 1 and 3 , with statistically significant differences between academic year $(p=0.001)$ (Table 2).

\section{Discussion}

Out of 115 participants, the majority positively responded to the statements assessing the benefits of PBL. These findings were similar to those previous studies (Barman et al., 2006; Ommar, 2011; Saalu et al., 2010). This study indicates that the School of Medicine has achieved the objectives of conducting PBL as one of the main teaching methods.

Regarding the disadvantages of PBL, more than half of the students responded that PBL is time consuming. This finding is similar to that of a study group in Nigeria (Saalu et al., 2010). Time consumption depends on the duration for searching literature, collecting new information, preparing presentations and the difficulty of the PBL trigger where students may need more time to study.

A majority agreed that some students dominate while others are passive in the discussion. The level of participation in PBL sessions varied among students. Poor participation of some students could be attributed to four main factors - content knowledge, English proficiency, facilitator's role and students' perception of these roles and social relationships between group members (Imafuku, 2007).

Comparison of the responses by different academic years on the benefits of PBL showed that significantly higher percentage of year 2 and year 3 students gave positive responses compared to year 1 students. Comparison of responses to disadvantages revealed that the mean rank of the responses from year 1 students was higher than that of other students. The reason may be that year 1 students had not adapted to the PBL method at the time of survey, whereas students in year 2 and 3 had experienced many PBL sessions and were mature enough for adult learning with time management.

\section{Conclusion}

The majority of the Phase 1 medical students of UCSI University perceive PBL sessions as effective for their learning and had positive attitude on the benefits of PBL. However, more 
than half of the students responded that PBL was time consuming and some students dominated in PBL session while others were passive in the discussion.

\section{Acknowledgement}

This study was carried out under the research grant (Proj-In-FMS-002) funded by Centre of Excellence for Research Value Innovation and Entrepreneurship (CERVIE). The authors express their special gratitude to Prof. Peh Suat Cheng, Dean of Faculty of Medicine and Health Sciences, UCSI University for allowing conduct of this study and to CERVIE for funding the project. The UCSI medical students who kindly participated in the study are also gratefully acknowledged.

\section{References}

Amin, Z. \& Khoo, H.E. (2009) Problem-based Learning: Concepts and Rationale,In Basics in Medical Education (2 $\left.{ }^{\text {nd }} E d\right)$ Singapore, World Scientific, pp.181-192.
Barman, A., Rogayah, J. \& Ismail, N.M. (2006) Problem-based learning as perceived by Dental students in Universiti Sains Malaysia, Malaysia Journal of Medical Sciences, 13, 1, pp.63-67.

Imafuku, R. (2007) Students' Academic Experience in Medical Problem-based Learning Tutorials, Proceeding of the Independent Association 2007 Japan Conference: Exploring theory, enhancing practice: Autonomy across the disciplines, Kanda University of International Studies, Chiba, Japan, October, Available at http://www.independentlearning.org (Accessed 2 April 2012)

Ommar, N. (2011) Perception of First and Second Year Medical Students on Problem-based Learning in Universiti Malaysia Sarawak. World Applied Science Journal, 14, 11, pp.1628-1634.

Saalu, L.C., Abraham, A.A. \& Aina, W.O. (2010) Quantitative evaluation of third year medical students' perception and satisfaction from problem based learning in Anatomy: A pilot study of the introduction of problem based learning into the traditional didactic medical curriculum in Nigeria, Educational Research and Review, 5, 4, pp.193-200. 